\title{
ANALYZING THE IMPACT OF TEACHING METHODS TOWARDS STUDENTS' ATTITUDES AND THEIR ACHIEVEMENTS IN MATHEMATICS AT SECONDARY SCHOOL LEVEL
}

\section{Lubna Shaheen}

M. Phil Scholar, Department of Education,

Sardar Bahadur Khan Women's University, Balochistan,

Pakistan

Email: anadil_shah@yahoo.co.uk

\author{
Aliya Ayub \\ Assistant Professor, Department of Education, \\ Sardar Bahadur Khan Women's University, Balochistan, \\ Pakistan
}

\section{Khadija Kareem}

Assistant Professor, Department of Education, Sardar Bahadur Khan Women's University, Balochistan, Pakistan

\begin{abstract}
Mathematics is a vital subject and it considered as the key to development in society. In the development and enhancement of society Mathematics has play a forthright act from pre-historic period to the present. It is essential to provide clear concepts of Mathematics to Students because at secondary school level every single subject has a connection with Mathematics and support students to grasp the concepts of supplementary subjects too. The purpose of this study was to describe the teaching methods and the relationship between students' attitude and their achievement in Mathematics at Secondary School Level. The data was collected from the questionnaire to be filled by the Mathematics teachers of class $9^{\text {th }}$. Secondly, a survey (Fennema Sharman attitude scale) of students' attitude towards Mathematics was carried out and an achievement test was conducted to assess the achievement level of students in the subject of Mathematics. The data was analyzed statistically. Findings show that teachers are using traditional methods of teaching Mathematics which are not that much useful for students to change their attitude in Mathematics and increase their
\end{abstract}




\section{KEYWORDS}

Mathematics Achievement, Student Attitude, Teaching Methods

\section{INTRODUCTION}

This is now very common phrase that "Mathematics is the mother of all sciences", which could lead that Mathematics has great influence on all the subjects whether from social sciences or pure sciences. And all the subjects facilitate and improves human lives and societies overall. Therefore, we can say that this subject facilitates us in our daily life and considered to be an essential tool (Mohamed \& Waheed, 2011).

Mathematics offers such opportunities to students for creative work and provide them moments of illumination and delight so we can say that mathematics is also a subject of pleasure and enthusiasm. To pursue mathematics beyond the classroom walls it requires ideas to be discovered and insights to be gained, to spur students (Bhattista, 1999).

As the authors of Principles and Standards for School Mathematics wrote, "There is no 'right way' to teach mathematics" (NCTM, 2000). However, we recognize that there are some mathematics teachers who are more effective than others. Teachers who claim to teach mathematics effectively, they do certain common things when delivering their mathematics instruction. These certain things can be their incline towards the student-discovery or the teacher-directed end of the continuum.

Sufficient knowledge of mathematics makes a good mathematics teacher (Fennema \& Franke, 1992). A teacher who teaches the subject of mathematics he or she should possess the comprehensive knowledge of the subject and capable to perceive connections between different concepts and fields (Ma, 1999). Mathematics Teachers should have a sufficient knowledge of subject matter to pursue the teaching and learning process effectively (Brown \& Borko, 1992). A mathematics teacher is required to understand the students' needs and thinking in order to satisfy their learning needs and to create such activities that guide meaningful learning towards mathematics. (Carpenter, Fennema, Peterson \& Carey, 1988). It is important for a teacher to take insight about students' attitude and misconception about the subject. 
As professionals, teachers need to drive their own professional development. The goal of any professional development program should be to build the capacity in the school faculty to be a partner with others in the mathematics community in the design and delivery of professional development experiences. There are different ways to teach mathematics effectively, but teachers' needs to have knowledge of three basic things. There are different ways to teach mathematics effectively, but teachers' needs to have knowledge of three basic things:

a) The material being taught.

b) The best instructional strategies to teach the learning material.

c) How efficiently student can learn"?

Learning Mathematics is not merely a cognitive trial, but additionally an affective one. The use of effective teaching methods makes the process of learning smoother and more valuable. The main objective of this study was to describe the teaching methods and to correlate the relationship between students' attitude and achievement in the subject of Mathematics at Secondary School level.

\section{LITERATURE REVIEW}

What is mathematics?

Relationships found in shapes and nature are all about Mathematics which illuminates all these. Mathematics is an influential way to express ideas and relationships in the form of numeric, graphics, symbols, verbal and pictorial forms. This wonder of mathematics is denied by many children. A study by Mendick et al. (2008), which was based on an extensive survey among British students, was summarized as follows: Many students and undergraduates seem to think of mathematicians as old, white, middle-class men who are obsessed with their subject, lack social skills and have no personal life outside mathematics. The student's views of mathematics itself included narrow and inaccurate images that are often limited to numbers and basic arithmetic.

\section{Teaching of mathematics and its importance at secondary school level}

Through the introduction of appropriate education reforms, almost all the countries including Pakistan make an effort to improve the quality of education. Through pre-service and in-service teacher education programs, a variety of initiatives like curriculum and resource development are initiated and efforts are made to make teaching learning process more effective and comprehensive. 
To provide better learning opportunities to students, teachers are encouraged to bring change in their teaching by using variety of teaching strategies and resources. Pakistan has undertaken curriculum development process by the coordination of federal as well as provincial public of Pakistan. This newly developed curriculum is now introduced in the schools. The new mathematics curriculum is developed and emphasized on learning of mathematics for conceptual understanding and to promote, among students, the reasoning and problem-solving skills. Therefore, it is needed that teachers change their prevailing mathematics teaching which only consist of emphasis on knowledge acquisition, drill and practice (Amirali 2000; Halai, Rizvi \& Rodrigues, 2007; Halai 2008;). Moreover, there is a need to bring change in current scenario of mathematics practices. National Curriculum for Mathematics (NCM) 2006, has been highlighted in the document that:

"the teachers' role has been rerouted from 'dispensing information' to planning investigative tasks, managing cooperative learning environment and supporting students' creativity in developing rational understanding of the concepts of mathematics".

Therefore, changes in teachers' beliefs, attitudes, and knowledge about the nature of mathematics teaching and learning this curriculum reform demands paradigmatic shifts for many teachers. (Susan, Swars, Smith, Smith, \& Hart, 2009).

\section{What is effective teaching of mathematics?}

After conducting large scale researches on teaching and learning mathematics it is answered that such kind of pedagogical approaches that engage learners in logical thinking, lead them towards desirable outcomes. Mathematics is one the most important and core subject and understanding of mathematical concepts influence decision making in all areas of life whether social, private and civil. Education of Mathematics is a key towards availing the school level as well as citizenship opportunities of young people. Like in past, today also there are so many students who struggled with mathematics and felt that it is a subject of disappointment because they continually encounter obstacles to understand it. Although it is difficult to describe that what is effective mathematics teaching and how students learn more in mathematics but teachers can play their role in practicing and elaborating the methods which are more applicable authentic and comprehensive according to their circumstances than others. 


\section{Mathematics pedagogy must:}

- be grounded in the general premise that all students have the right to access education and the specific premise that all have the right to access mathematical culture;

- $\quad$ acknowledge that all students, irrespective of age, can develop positive mathematical identities and become powerful mathematical learners;

- be based on interpersonal respect and sensitivity and be responsive to the multiplicity

of cultural heritages, thinking processes, and realities typically found in our classrooms;

\section{Achievement in the subject of Mathematics}

In his research Muhammad (2002) accounts that, the learning of mathematics based on just memorization of the mathematical problems given in the textbook. Student memorize these rules without the understanding of these concepts (Ali, T., 2011). For poor quality of mathematics education, wide range of factors are responsible in main stream public schools of Pakistan. There are many factors in lower school performance in mathematics such as poor subject knowledge of teachers, lacking in pedagogical competence of teachers and perceptions about mathematical knowledge of students and teachers. All these factors obstruct students from developing an understanding of mathematical knowledge. (Amirali \& Halai, 2010).

In Baluchistan, in the core curriculum subjects like mathematics, there is no evidence of any systematic and in-depth research about the student learning at secondary level. However, at Pakistan level, some researchers at primary level were conducted. These studies reflect the impenetrable picture of the students of mathematics. At this stage the level of achievement of students in core curriculum subjects like science and mathematics is described.

In Pakistan, the emphasis is given to the desire to see students to memorize and recall factual information provided in the textbook rather than developing logical thinking. The problem or issue of low achievement is primarily started from this concept of learning, and it is happening in many mathematics classrooms of Pakistan. Despite of the fact that mathematics is an important and significant subject and the accepted academic value of it, the in-depth student learning in mathematics is not usually treated as the focal point of all the classroom activities at secondary level. Our students and teachers faced every 
day in Mathematics, an obvious scarcity of the contextualized understanding of the challenges in the teaching and learning of mathematics. That is why the achievement level of students in mathematics is low.

\section{Attitude of students towards mathematics}

In the teaching and learning processes, attitude towards mathematics plays a vital role. Attitude has the ability to effects achievement of students in mathematics. There are many factors that affect student attitude towards mathematics like teaching methods, the structure of the school, family, peer group and attitude of students towards school.

There is barren affect that usually presenting of mathematics in classroom is not logical and the way it is perceived by the students, even teachers believe that they are presenting it in an authentic and context dependent way becomes the reason for many students to leave this subject. (Barton, 2000; Furinghetti and Pekhonen, 2002). These Researches estimated that if students have positive attitude towards mathematics, it leads them towards success in mathematics. To improve achievement and provide base at higher level in the subject of mathematics it is attempted to improve attitude towards mathematics at lower level. At secondary school level, it also causes effect in achievement of mathematics (Ma and $\mathrm{Xu}, 2004$ ).

\section{OBJECTIVES}

1. To analyze the teaching methods usually in practice by the teachers of Mathematics at secondary school level.

2. To correlate students' attitudes and their achievement in the subject of Mathematics.

\section{RESEARCH QUESTIONS}

1. What are the teaching methods usually in practice by the teachers of Mathematics at secondary school level?

2. Whether attitude and achievement are significantly correlated in the subject of Mathematics?

\section{RESEARCH METHODOLOGY}

The type of this research was Quantitative which was mainly concerned with describing the present phenomena of the concerned issue. Questionnaire was used for both students and teachers to collect required data. A self-made test 
was used to collect the required data from students. Therefore, this study was totally designed on the basis of quantitative methods. The information collected through the tools was coded and analyzed through Microsoft excel. This investigation was mainly started through brief literature review. Through literature review teaching methods were grouped into categories. To enhance the categories for the purposes of designing of questionnaires, teaching methods obtained from literature. Algebra and Geometry were added to the categories and tested for their content validity. This process culminates with the exploration of the combination of independent variables, teaching method types resulting in a more accurate explanation of their relationship to students' achievement in Algebra and Geometry as the dependent variable. As sample, 50 public and private schools were selected and 50 male and female mathematics teachers were also selected as sample of the study. Total sampled students were 500 in which 250 male and 250 female students were selected as sample.

\section{DATA ANALYSIS}

Results showed that in Quetta, city of Baluchistan, Pakistan, Mathematics teachers both in Public and Private sector are using indigenous methods of teaching mathematics like re call and memorization of facts.

As the study basically revolves around finding the relationship between teaching methods and students' achievement and to correlate students' attitude and their achievement in the subject of mathematics, the results showed that:

\section{Table 1}

Correlation between teaching methods and student's achievement.

\begin{tabular}{llcc}
\hline & & $\begin{array}{c}\text { Teaching } \\
\text { methods }\end{array}$ & $\begin{array}{c}\text { Students } \\
\text { achievement }\end{array}$ \\
\hline $\begin{array}{l}\text { Teaching } \\
\text { methods }\end{array}$ & Pearson Correlation & 1.000 & .75 \\
& Sig. (2-tailed) &. & .64 \\
$\begin{array}{l}\text { Students } \\
\text { achievement }\end{array}$ & Pearson Correlation & .75 & 1.000 \\
& Sig. (2-tailed) & .64 &. \\
\hline
\end{tabular}


Table shows that there is a strong relationship between teaching methods and students' achievement. Teaching methods effects students' achievement in the subject of Mathematics and these variables have strong relationship.

\section{Table 2}

Correlation between attitude and achievement in the subject of mathematics.

\begin{tabular}{lllll} 
Variables & N & Mean & SD & R \\
\hline Achievement & 13843 & 27.79719 & 27.79719 & 0.72 \\
Attitude & 102312 & 2.657593 & 2.657593 & 0.78 \\
\hline
\end{tabular}

Table reflects the relationship between student's attitude and their achievement. Better attitude refers to high achievement and low achievement refers to squat attitude towards Mathematics. Both the variables have strong relationship.

\section{FINDINGS \& RESULTS}

The teaching strategies used by public and private schools' teachers at secondary school level have no huge difference. Both the educational sectors, are using indigenous methods of teaching mathematics at secondary school level. These methods include Explain, demonstrate, and provide solutions to the problems, recall and memorize of facts.

The results depict that the attitude of students towards mathematics is not much positive at secondary level of both public and private schools. Most of the students feel nervous and have no likeness to the subject of mathematics.

Student's achievement analyzed by their test scores shows that the achievement level of public-school students and private school students is low in the subject of mathematics at secondary school level.

The study results reveal that challenges faced by the public schools' teachers are more than private school teachers. Moreover, both sectors are facing challenges in the field of teaching mathematics. The results depict that the assessment practices used by the public-school teachers are little better than private school teachers of mathematics at Quetta city but these assessment practices are not comprehensive and modern. 
Results shows that the attitude towards mathematics of private and publicschool students is not positive. Most of the students from public and private schools don't like the subject of mathematics. The findings of the study indicate that mean score of public-school students in achievement test is low than private school students as well as private school students' mean score is higher than public school students in Fennoman Sherman attitude scale. The findings of the study also indicate that the overall achievement level in Mathematics, is low and attitude of Public and Private School students' is not so positive.

Findings show that teachers are using teaching strategies like Explain, demonstrate, and provide solutions to the mathematical problems. The second strategy they are using is Provide time for practice of Mathematical problems.

Most of the teachers think that group work and class discussion is very effective method to teach mathematics. Findings show that students coming from wide variety of backgrounds is a great challenge for teachers to teach Mathematics. Most of the teachers from Public and Private Schools are more focused on teaching numbers and operations.

Most of the teachers use text books, work sheets, calculators and teachers' guide as resource to teach assess students' skills. The study results indicate that there is a strong relationship between students' achievement and teaching methods. Both the variables are highly correlated. The results reveal that students 'achievement and their attitude towards mathematics are significantly correlated.

\section{DISCUSSION}

Mathematics is a vital subject and it is the key to advancement in society. In the development and enhancement of society Mathematics has play a forthright act from pre-historic period to the present. The purpose of this study was to describe teaching methods and relationship between students' attitude and their achievement in Mathematics at Secondary School Level in Quetta city Pakistan. The study also aims to find out the relationship between teaching methods and students' achievement. have significant effects on students' attitude and achievement in the subject of Mathematics, and which teaching methods are effective in teaching of Mathematics at secondary level? This research paper argued whether attitude and achievement are significantly correlated? The data was collected from the questionnaire to be filled by the 
Mathematics teachers of class $9^{\text {th }}$. The questionnaire focused on teachers' views on Mathematics teaching, their perceptions of how to develop students' attitude in Mathematics, their awareness of using different strategies, and teaching practices related to achievement in Mathematics. Secondly, a survey (Fennema Sharman attitude scale) of students' attitude towards Mathematics was carried out and an achievement test was conducted to assess the achievement level of students in the subject of Mathematics. The data was analyzed statistically.

Ultimately, it was sought that Mathematics teachers in Quetta city are doing well but they do not teach Mathematics by using modern teaching pedagogies to develop students' skills and reasoning in the subject of Mathematics. The findings also explicitly reveal that these teachers do not have information about modern approaches that are widely used for teaching of Mathematics. The teachers are using traditional methods of teaching Mathematics which are not that much useful for students to change their attitude in Mathematics and increase their achievement also. The classrooms instructions are influenced by examination system where the students are indulged to memorize the facts, figures, rules and processes from their textbooks and reproduce them. There is no practical implication of Mathematics rules in students' daily life that's why there is no interest of students in this subject. In conclusion, research findings indicate a dire need to bring improvement in the teaching and learning practices of Mathematics. Mathematics plays an important role in a child's educational development. The study sets a direction with some recommendations for teachers in this particular context.

\section{RECOMMENDATIONS}

Recommendations for education department, educational administrators, head teachers, teachers, parents, and other stake holders.

The results of this study should be of use to education department, educational administrators, head teachers, teachers, parents, and other stake holders faced with the problem of low achievement level of students in the subject of mathematics. It is assumed that most of the students have no interest in the subject of mathematics and their attitude is negative towards mathematics. We deal mathematically in our daily life; therefore, it is important to have basic skills in this subject. At school level, many factors effect on students learning in this specific subject i.e., gender, parents support, students' motivation, teachers' qualifications, teachers' interest, curriculum peers support, 
curriculum and assessment methods. This study explored the effects of teaching methods on students' attitude and achievement in Mathematics. Therefore, based on the findings of this study it should be recommended that:

\section{For teachers}

Teachers should advance and improve their teaching methods and assessment practices at secondary school level in the subject of mathematics. More they would be able to identify and solve students' individual problems and differences through their teaching methods and guide them in a more accurate, comprehensive and practical way so that students change their attitude towards the subject of mathematics and improve their achievement in this subject. For the improvement of teaching methods, it is needed that government as well as private schools must conduct some workshops, seminars and other related trainings and refresher courses for the teachers to improve their skills and teaching methods.

\section{For administrators}

For administrators, it is recommended that they should observe and identify the traits or skills while selecting teachers for the subject of Mathematics, which will automatically improve their students' success rate and reputation of their schools in general. There should be fair selection of the teachers so that eligible people lead this important subject and guide the nation's future generation.

\section{For education department}

Education department should provide best possible infrastructure and material to the students and teachers of mathematics to improve their skills. Mathematics labs should be built in the schools so that students and teachers can test the principles of mathematics.

Mathematics syllabus should be developed according to the level and needs of the secondary school students. It should comprise of the knowledge that must be applicable in their daily life and will guide them for future learning.

\section{For parents}

Parents should give proper attention to the education of their children especially the subject of mathematics as it is the base of every subject. It is ethical for parents to search for the school and teacher who is more reliable in its provision of education. 


\section{REFERENCES}

Ali, T. (2011). Exploring Students' Learning Difficulties in Secondary Mathematics Classroom in Gilgit-Baltistan and Teachers' Effort to Help Students Overcome These Difficulties. Bulletin of Education and Research, 33(1).

Amirali, M., \& Halai, A. (2010). Teachers' Knowledge about the Nature of Mathematics: A Survey of Secondary School Teachers in Karachi, Pakistan. Bulletin of Education and Research, 32(2).

Barton, A. C. (2000). Crafting multicultural science education with preservice teachers through service-learning. Journal of Curriculum Studies, 32(6), 797-820.

Battista, M. T. (1999). The mathematical miseducation of America's youth. Phi Delta Kappan, 80(6), 424.

Borko, H., Eisenhart, M., Brown, C. A., Underhill, R. G., Jones, D., \& Agard, P. C. (1992). Learning to teach hard mathematics: Do novice teachers and their instructors give up too easily?. Journal for research in mathematics education, 194-222.

Carpenter, T. P., Fennema, E., Peterson, P. L., \& Carey, D. A. (1988). Teachers' pedagogical content knowledge of students' problem solving in elementary arithmetic. Journal for research in mathematics education, 385-401.

Farooq, M. S., \& Shah, S. Z. U. (2008). Students'attitude Towards Mathematics. Pakistan Economic and Social Review, 75-83.

Fennema, E., \& Franke, M. L. (1992). Teachers' knowledge and its impact.

Furinghetti, F., \& Pehkonen, E. (2002). Rethinking characterizations of beliefs. In Beliefs: A hidden variable in mathematics education? Springer Netherlands, 39-57

Halai, A., Rizvi, N., \& Rodrigues, S. (2007). State of mathematics and science education in Pakistan: A review. Aga Khan University Institute for Educational Development Karachi, Pakistan. Paper submitted to Ed Qual. Funded by DFID. Retrieved on January, 1, 2008.

Ma, L. (1999). Knowing and teaching elementary mathematics: Teachers' understanding of fundamental mathematics in China and the United States. Mahwah, NJ: Lawrence Erlbaum Associates.

Mendick, H., Epstein, D., \& Moreau, M. P. (2007). Mathematical Images and Identities: Education, Entertainment, Social Justice: End of Award Report (RES-000-23-1454).

Mohamed, L., \& Waheed, H. (2011). Secondary students' attitude towards mathematics in a selected school of Maldives. International Journal of humanities and social science, 1(15), 277-281.

National Council of Teachers of Mathematics (Ed.). (2000). Principles and standards for school mathematics, 1 , National Council of Teachers of.

National Curriculum for Mathematics (2006). Ministry of Education, Government of 
Pakistan Journal of Educational Research. Vol 1. Issue 2 (2018) Analyzing the impact..

Pakistan. Retrieved from http://www.moe.gov.pk/Curriculum.htm

Swars, S. L., Smith, S. Z., Smith, M. E., \& Hart, L. C. (2009). A longitudinal study of effects of a developmental teacher preparation program on elementary prospective teachers' mathematics beliefs. Journal of Mathematics Teacher Education, 12(1), 47-66. 